\title{
Part-list cuing with and without item-specific probes: The role of encoding
}

\author{
Alp Aslan ANd Karl-Heinz BäUML \\ Regensburg University, Regensburg, Germany
}

\begin{abstract}
Part-list cuing - the detrimental effect of the presentation of a subset of studied items on recall of the remaining noncue items - was examined in three different study conditions and in the presence and absence of the noncues' initial letters serving as item-specific probes. With a single study trial, part-list cuing was observed both with and without item-specific probes. By contrast, when participants received two study-test cycles or interrelated list items to a common story, part-list cues were found to be detrimental only in the absence of itemspecific probes, but not in their presence. These results indicate that the role of item-specific probes in part-list cuing depends on encoding. The findings are consistent with a recent two-mechanism account of part-list cuing (Bäuml \& Aslan, 2006), according to which two different mechanisms mediate the effect in different encoding situations.
\end{abstract}

A finding that has attracted the attention of memory researchers for almost forty years is part-list cuing (Slamecka, 1968). Part-list cuing refers to the intriguing observation that the presentation of a subset of previously learned items as retrieval cues often does not facilitate but rather impairs recall of the remaining noncue items (Roediger, 1973; Slamecka, 1968). Although initially dismissed as a procedural artifact (Slamecka, 1968, p. 510), partlist cuing has since proven to be a very robust effect that emerges in a variety of experimental contexts. Indeed, detrimental effects of part-list cues have been demonstrated with related and unrelated material (Slamecka, 1968), with intralist and extralist cues (Watkins, 1975), in different age groups (Marsh, Dolan, Balota, \& Roediger, 2004; Zellner \& Bäuml, 2005), and even in false memory settings (Kimball \& Bjork, 2002; Reysen \& Nairne, 2002).

Accounts of part-list cuing have typically been based on the idea that a single mechanism is responsible for the effect (see Nickerson, 1984, or Roediger \& Neely, 1982, for reviews). The strategy disruption account, for instance, assumes that the presentation of part-list cues disrupts retrieval by forcing a serial recall order that disagrees with the participant's subjective organization of the list (D. R. Basden \& B. H. Basden, 1995; D. R. Basden, B. H. Basden, \& Galloway, 1977). In line with this view, part-list cuing has been found to be reduced or even eliminated when the cues are consistent with the participant's preferred recall order (B. H. Basden, D. R. Basden, \& Stephens, 2002; D. R. Basden \& B. H. Basden, 1995). Also in line with strategy disruption is the observation that the detrimental effect of part-list cues disappears when the cues are removed in a subsequent memory test (D. R. Basden \& B. H. Basden, 1995; D. R. Basden et al., 1977).
In fact, the absence of the cues in the second test should permit participants to return to their original strategies and thus eliminate the forgetting.

A more recent single-mechanism account of part-list cuing is retrieval inhibition (Bäuml \& Aslan, 2004; see also Anderson, Bjork, \& Bjork, 1994). According to this account, the presence of part-list cues at testing leads to early covert retrieval of the cue items. This covert retrieval is assumed to trigger inhibitory processes on the noncue items, affecting the representation of the noncues itself and thus lowering their recovery chances. Covert retrieval, therefore, should be similar in nature to overt retrieval, which, in studies on retrieval-induced forgetting, has been shown to inhibit the nonretrieved material (see Anderson, 2003, for a review of retrieval-induced forgetting). Indeed, studies that compared part-list cuing and retrieval-induced forgetting directly within single experiments found neither qualitative nor quantitative differences between the two forms of forgetting (Bäuml \& Aslan, 2004; Bäuml \& Kuhbandner, 2003; Zellner \& Bäuml, 2005). ${ }^{1}$

Part-list cuing has mostly been examined using a testing procedure in which a subset of the studied items was provided as part-list cues and participants were asked to recall the remaining noncue items in any order. However, other testing procedures have been employed as well. Partlist cuing was examined when the noncues' initial letters were provided as additional cues (Bäuml \& Aslan, 2004; Bäuml, Kissler, \& Rak, 2002; Kissler \& Bäuml, 2005; Peynircioğlu, 1989) or when memory of the noncues was assessed by means of a recognition test (Neely, Schmidt, \& Roediger, 1983; Oswald, Serra, \& Krishna, 2006; Todres $\&$ Watkins, 1981). In all of these studies, reliable part-list cuing arose, indicating that the presence of item-specific

K.-H. Bäuml, karl-heinz.baeuml@psychologie.uni-regensburg.de 
probes for the to-be-remembered noncues does not eliminate the detrimental effect of part-list cues.

Finding part-list cuing in the presence of item-specific probes agrees with the inhibition account of part-list cuing. According to the inhibition account, the detrimental effect should affect the representation of the noncue items itself and thus be present not only in the absence but also in the presence of item-specific probes. On the other hand, the finding challenges the strategy disruption account. Indeed, forcing participants to use experimenter-provided (random) retrieval "strategies," as is typically done in item-specific tests, should disrupt participants' subjective strategies regardless of whether part-list cues are provided (Peynircioğlu, 1989). Thus, following one-mechanism accounts of part-list cuing, the finding of part-list cuing in the presence of item-specific probes speaks strongly in favor of inhibition and challenges strategy disruption.

Concluding from this result that strategy disruption does not contribute to part-list cuing might be premature, however, as indicated by the results of a recent study in which part-list cuing was found to be transient and lasting (Bäuml \& Aslan, 2006). In this study (Bäuml \& Aslan, 2006), part-list cuing was examined using a repeatedtesting procedure, in which part-list cues were provided in the first test but not in the subsequent second test. Two types of study conditions were contrasted: (1) study conditions that favor the formation of interitem associations and the building up of serial retrieval plans, as is the case when participants are put through repeated study-test cycles or are instructed to encode items serially (e.g., B. H. Basden et al., 2002; D. R. Basden \& B. H. Basden, 1995; D. R. Basden et al., 1977; Serra \& Nairne, 2000; see also Tulving, 1962); and (2) study conditions that favor the formation of interitem associations to a much lesser extent and in which elaborated retrieval plans are typically not built up, as is the case when participants receive just a single study trial, and no instruction to encode the items strategically is provided (e.g., Bäuml \& Aslan, 2004; Bäuml et al., 2002; Neely et al., 1983; Oswald et al., 2006). Whereas part-list cuing was found to be transient in the first type of study condition - a finding consistent with strategy disruption (D. R. Basden \& B. H. Basden, 1995) - the effect was lasting in the second type, which is consistent with retrieval inhibition (Anderson et al., 1994). Thus, though operating in different encoding conditions, both retrieval inhibition and strategy disruption may mediate the detrimental effect of part-list cues (Bäuml \& Aslan, 2006).

Following this two-mechanism account, both the persistency of part-list cuing and the role of item-specific probes in this form of forgetting should depend on study condition. Indeed, study conditions that favor the formation of interitem associations and the building up of serial retrieval plans should trigger strategy disruption processes, showing part-list cuing in the absence of itemspecific cues, but not in their presence. In contrast, study conditions that do not favor the formation of interitem associations should trigger inhibitory processes on the noncues, showing part-list cuing regardless of whether item-specific cues are provided. To the best of our knowledge, there is no study to date that examines the role of item-specific probes for the two types of study conditions. The present study addresses the issue.

\section{The Experiment}

Participants learned items under three different study conditions: (1) a 1-study condition, in which the material was presented once without any test trial or instruction to encode the items serially (Bäuml \& Aslan, 2004); (2) a 2-study-test condition, in which participants were put through two successive study-test cycles (D. R. Basden \& B. H. Basden, 1995); and (3) a story condition, in which the material was presented once, but participants were instructed to encode the items in terms of a common story (Sahakyan \& Delaney, 2003). After a subsequent distractor task, a recall test was conducted in which the participants were asked to recall the previously studied material. In this test, either a subset of the learned items was provided as part-list cues or no part-list cuing occurred at all. Half of the participants in each of the three study conditions received the noncues' initial letters as item-specific probes, and the other half did not receive such probes.

Results from prior work suggest that in the 1-study condition, interitem associations and serial representations play only a minor role, whereas in the 2-study-test and the story conditions, they play a major role (e.g., D. R. Basden \& B. H. Basden, 1995; Bäuml \& Aslan, 2006; see also Anderson \& McCulloch, 1999, for a related demonstration). On the basis of the two-mechanism account, we suspected that part-list cuing was mediated by retrieval inhibition in the 1-study condition and by strategy disruption in the 2 -study-test and the story conditions. Accordingly, in the 1-study condition, detrimental effects of part-list cues should be observable in both the presence and the absence of item-specific probes, whereas in the 2-study-test and story conditions, the detrimental effects should arise only in the absence of the probes.

\section{METHOD}

\section{Participants}

One hundred and forty-four students at Regensburg University participated in the experiment. They were tested individually.

\section{Materials}

Two item lists were constructed, each consisting of 20 unrelated common nouns drawn from several published norms (Battig \& Montague, 1969; Scheithe \& Bäuml, 1995). Within each list, no two items began with the same first letter. English translations of the originally German items are available on request via e-mail.

\section{Design}

The experiment had a mixed design with three factors: study, testing, and cuing. Study (1-study, 2-study-test, story) and testing (itemspecific probes, no item-specific probes) were manipulated between participants; cuing (part-list cuing, no part-list cuing) was varied within participants. For each participant, the experiment consisted of two parts, which differed according to which of the two lists had to be learned and whether part-list cues were provided. Each part consisted of two main phases: an initial study phase and a test phase. In the study phase, one third of the participants received a single study trial without any test trial (1-study condition), one third underwent two successive study-test trials (2-study-test condition), and the final third made up a story including the to-be-learned items (story 
condition). In the test phase, half of the participants in each study condition were tested in the presence of item-specific probes, and the other half were tested in the absence of such probes. In one of the two parts of the experiment, participants were provided with half of the studied items as retrieval cues for recall of the remaining items (part-list cuing); in the other part, they were asked to recall all of the previously studied items without being provided any part-list cues (no part-list cuing). The order of the part-list-cuing and no-part-listcuing conditions was counterbalanced across participants.

\section{Procedure}

Study phase. The 20 items of a list were presented successively and in random order at a 5 -sec rate on index cards. Whereas participants in the 1-study condition received only one such study trial, participants in the 2-study-test condition went through two study-test trials. After the first study trial, these participants did a 30 -sec backward-counting task and were then given a first recall test, in which they were asked to write down all of the previously studied items in any order they wished for $2 \mathrm{~min}$. Promptly following this first study-test trial, a second study-test trial was conducted in exactly the same way. To facilitate associative encoding, the presentation order of the items was kept constant across the two study trials. In the story condition, participants were asked to generate a meaningful sentence from each presented word and to interrelate these sentences to a common story. They were told to say the sentences aloud to ensure compliance with the instruction (see Bäuml \& Aslan, 2006, and Sahakyan \& Delaney, 2003). The study phase ended with a 1-min backward-counting task as a recency control.

Test phase. At test, participants were either asked to recall all of the previously studied items (no part-list cuing), or were provided with a random half of the items on top of a sheet of paper, in which case they were asked to read these items aloud and use them as retrieval cues for recall of the remaining items (part-list cuing). Those participants who received no item-specific probes were given $2 \mathrm{~min}$ to write down the to-be-remembered items in any order they wished. This held in both the part-list-cuing and no-part-list-cuing conditions. For those participants who received item-specific probes, the recall order was guided by the experimenter. This was done by successively providing the unique first letters of the to-be-remembered items in random order. Participants were given $6 \mathrm{sec}$ to write down a to-be-remembered item. In the no-part-list cuing condition, all of the previously studied items were tested in this manner; in the part-list cuing condition, only the noncue items had to be remembered. The material was counterbalanced so that, across participants, each item served equally often as a cue and noncue item.

\section{RESULTS}

\section{Performance in the Study Phase}

As reported in Table 1, in the study phase of the 2-studytest condition, recall performance improved significantly from $62.2 \%$ in the first test to $84.7 \%$ in the second test $\left[F(1,46)=174.7, M S_{\mathrm{e}}=.014, p<.001\right]$, thus reflecting successful learning. There was no difference in recall level between the part-list-cuing and no-part-list-cuing condi- tions $[F(1,46)<1]$, and no difference between the itemspecific-probes and no-item-specific-probes conditions $[F(1,46)<1]$. Both null effects were expected given that, up to this point, neither the cuing nor the testing manipulation had been introduced.

\section{Performance in the Test Phase}

The results of the test phase are shown in Figure 1. Regarding the 1-study condition (panel A), recall was lower in the presence than in the absence of part-list cues $(42.9 \%$ vs. 53.7\%), and it was slightly lower in the presence than in the absence of item-specific probes (45.4\% vs. $51.2 \%)$. Otherwise, the detrimental effect of part-list cues was about the same with and without the item-specific probes $(12.5 \%$ vs. $9.1 \%)$. A $2 \times 2$ ANOVA with the factors of cuing (part-list cuing vs. no part-list cuing) and testing (item-specific probes vs. no item-specific probes) showed a significant main effect of cuing $\left[F(1,46)=14.9, M S_{\mathrm{e}}=\right.$ $.019, p<.001]$, but no main effect of testing $[F(1,46)=$ $\left.1.1, M S_{\mathrm{e}}=.072, p=.29\right]$, and no interaction between the two factors $[F(1,46)<1]$. These results indicate that the presence of part-list cues reliably impaired recall and that this impairment was the same irrespective of whether item-specific probes were provided. In fact, significant forgetting arose both in the absence of item-specific probes $\left[F(1,23)=4.3, M S_{\mathrm{e}}=.023, p<.05\right]$ and in their presence $\left[F(1,23)=13.0, M S_{\mathrm{e}}=.014, p=.002\right]$.

Regarding the 2-study-test condition (panel B), recall was again lower in the presence than in the absence of partlist cues $(70.0 \%$ vs. $76.2 \%)$, and it was lower in the presence than in the absence of item-specific probes $(64.0 \%$ vs. $82.3 \%$ ). This time, the detrimental effect of part-list cues proved to be much smaller when item-specific probes were provided than when they were not provided $(0.4 \%$ vs. $12.0 \%$ ). A $2 \times 2$ ANOVA with the factors of cuing (partlist cuing vs. no part-list cuing) and testing (item-specific probes vs. no item-specific probes) showed significant main effects of cuing $\left[F(1,46)=6.5, M S_{\mathrm{e}}=.014, p<.02\right]$ and testing $\left[F(1,46)=15.0, M S_{\mathrm{e}}=.054, p<.001\right]$ and $\mathrm{a}$ significant interaction between the two factors $[F(1,46)=$ $\left.5.7, M S_{\mathrm{e}}=.014, p<.03\right]$. These results indicate that the presence of item-specific probes reliably influenced the part-list cuing effect. Indeed, part-list cues impaired recall only in the absence of the probes $\left[F(1,23)=18.3, M S_{\mathrm{e}}=\right.$ $.010, p<.001]$, not in their presence $[F(1,23)<1]$.

Regarding the story condition (panel C), recall was once again lower in the presence than in the absence of part-list cues $(64.1 \%$ vs. $69.5 \%)$, and lower in the presence than in the absence of item-specific probes $(57.0 \%$ vs. $76.6 \%)$. As

Table 1

Percentage of Recalled Items (\%RI) in the Study Phase of the 2-Study-Test Condition, With Standard Errors

\begin{tabular}{|c|c|c|c|c|c|c|c|c|}
\hline \multirow[b]{3}{*}{ Type of Test } & \multicolumn{4}{|c|}{ Trial 1} & \multicolumn{4}{|c|}{ Trial 2} \\
\hline & \multicolumn{2}{|c|}{$\begin{array}{l}\text { Part-List } \\
\text { Cuing }\end{array}$} & \multicolumn{2}{|c|}{$\begin{array}{l}\text { No Part-List } \\
\text { Cuing }\end{array}$} & \multicolumn{2}{|c|}{$\begin{array}{l}\text { Part-List } \\
\text { Cuing }\end{array}$} & \multicolumn{2}{|c|}{$\begin{array}{l}\text { No Part-List } \\
\text { Cuing }\end{array}$} \\
\hline & $\% \mathrm{RI}$ & $S E$ & \%RI & $S E$ & $\% \mathrm{RI}$ & $S E$ & $\% \mathrm{RI}$ & $S E$ \\
\hline No item-specific probes & 61.7 & 4.0 & 63.8 & 4.3 & 85.4 & 2.9 & 87.9 & 2.9 \\
\hline Item-specific probes & 58.3 & 4.3 & 65.0 & 4.8 & 82.5 & 3.0 & 82.9 & 3.2 \\
\hline
\end{tabular}



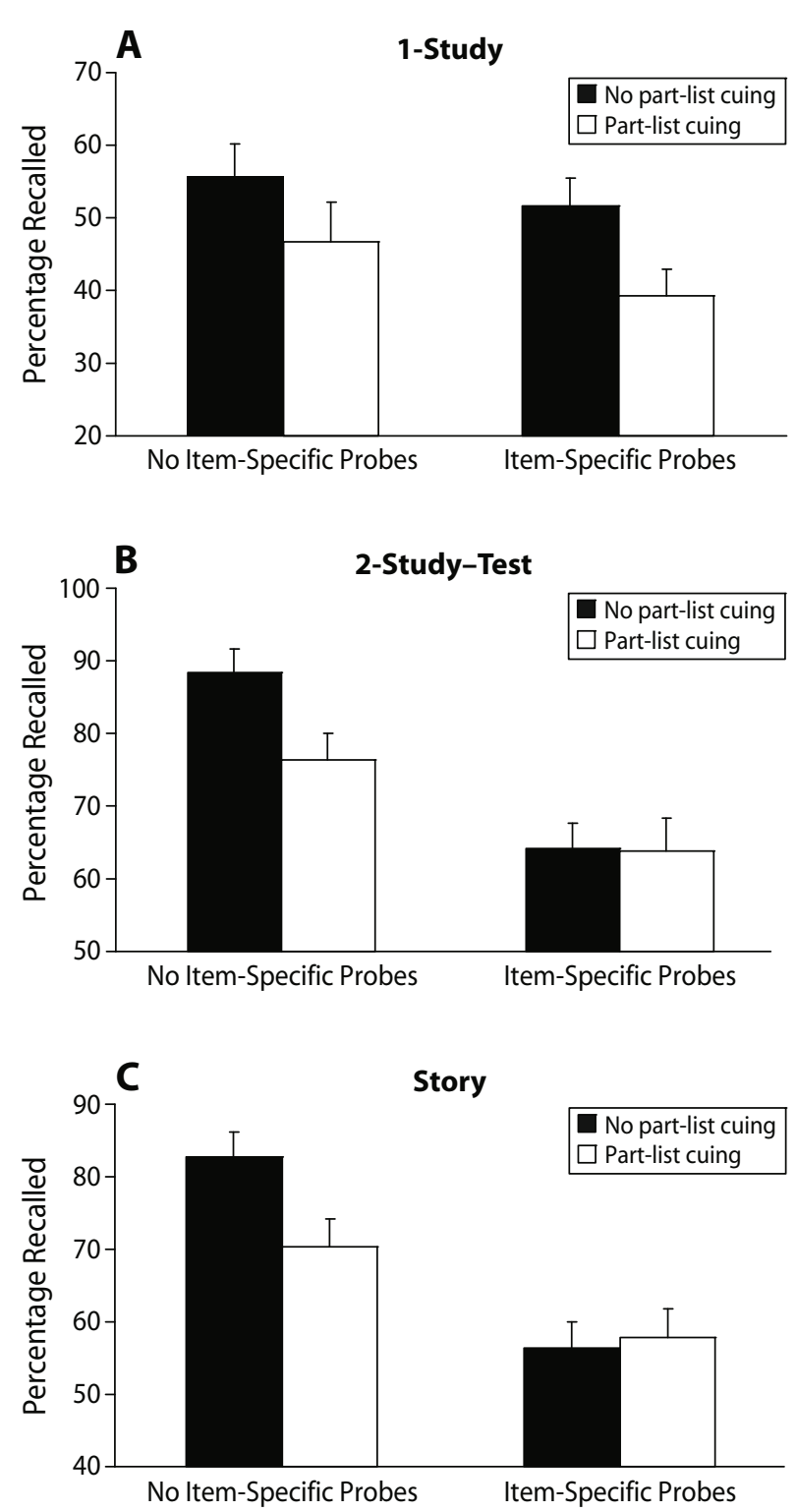

Figure 1. Mean recall performance and standard errors as a function of testing condition (item-specific probes, no item-specific probes) and cuing condition (part-list cuing, no part-list cuing) for the 1-study study condition (panel A), the 2-study-test study condition (panel B), and the story study condition (panel C).

in the 2-study-test condition, the detrimental effect of partlist cues proved to be smaller when item-specific probes were provided than when they were not provided $(-1.6 \%$ vs. $12.5 \%$ ). A $2 \times 2$ ANOVA with the factors of cuing (part-list cuing vs. no part-list cuing) and testing (itemspecific probes vs. no item-specific probes) revealed a marginal significant main effect of cuing $[F(1,46)=3.0$, $\left.M S_{\mathrm{e}}=.024, p=.09\right]$, a significant main effect of testing $\left[F(1,46)=25.1, M S_{\mathrm{e}}=.037, p<.001\right]$, and a significant interaction between the two factors $\left[F(1,46)=4.9, M S_{\mathrm{e}}=\right.$ $.024, p<.04]$. Significant forgetting arose only in the absence of item-specific probes $\left[F(1,23)=17.3, M S_{\mathrm{e}}=\right.$ $.011, p<.001]$, not in their presence $[F(1,23)<1]$.
Together, the results for the three study conditions suggest that the presence of item-specific probes reduces the forgetting in the 2-study-test and story conditions, but not in the 1-study condition. Comparing performance in the 2study-test condition with performance in the 1-study condition, a $2 \times 2 \times 2$ ANOVA with the three factors of study (1-study vs. 2-study-test), testing (item-specific probes vs. no item-specific probes), and cuing (part-list cuing vs. no part-list cuing) consistently revealed a significant interaction among the three factors $\left[F(1,92)=4.0, M S_{\mathrm{e}}=\right.$ $.017, p<.05]$. The same three-way interaction emerged when we compared performance in the story condition with performance in the 1 -study condition $[F(1,92)=4.2$, $\left.M S_{\mathrm{e}}=.022, p<.05\right]$.

\section{DISCUSSION}

Previous work showed that the presence of itemspecific probes for the to-be-remembered noncue items does not eliminate the detrimental effects of part-list cues (Bäuml \& Aslan, 2004; Bäuml et al., 2002; Kissler \& Bäuml, 2005; Neely et al., 1983; Oswald et al., 2006; Peynircioğlu, 1989; Todres \& Watkins, 1981). On the one hand, the present results replicate this finding by showing part-list cuing both in the absence and presence of itemspecific probes in the 1-study condition. On the other hand, the present results go beyond this previous finding by showing that it does not hold true in general. Indeed, both in the 2-study-test condition and the story condition, part-list cuing was found only in the absence and not in the presence of item-specific probes, thus indicating that the study condition influences the role of item-specific probes. While interesting in its own, this effect of study condition imposes important restrictions on theories of part-list cuing.

Indeed, the present effect of study condition challenges one-mechanism accounts of part-list cuing, which are solely based on retrieval inhibition or strategy disruption. Strategy disruption predicts detrimental effects of partlist cues only in memory tests that allow participants to apply their personal retrieval plans, and thus predicts no forgetting in tests using item-specific probes. The finding of significant forgetting in the presence of item-specific probes, as observed in the 1-study condition, is, therefore, inconsistent with strategy disruption. By contrast, retrieval inhibition assumes that part-list cuing is caused by an impairment in the memory representation of noncue items, so forgetting should be observable in all types of memory tests. The finding of no forgetting in the presence of item-specific probes, as observed in the 2-study-test and story conditions, thus disagrees with inhibition.

Bäuml and Aslan (2006) suggested that part-list cuing is caused by two different mechanisms that mediate the effect in different encoding situations. They argued that (1) strategy disruption mediates the effect in study conditions that favor the formation of interitem associations and the building up of serial retrieval plans, and (2) retrieval inhibition mediates the effect in study conditions, in which interitem associations and retrieval plans play 
only a minor role. The present results are consistent with the two-mechanism account by showing that the type of encoding determines whether part-list cuing occurs in the presence of item-specific probes. In the 2-study-test and story conditions, in which interitem associations are supposed to play a major role, part-list cuing occurred in the absence but not in the presence of item-specific probes; this is consistent with strategy disruption. In the 1-study condition, in which interitem associations are supposed to play only a minor role, part-list cuing occurred in both the absence and presence of item-specific probes; this is consistent with retrieval inhibition.

We argue above that, according to strategy disruption, no detrimental effects of part-list cues should arise in the presence of item-specific probes. The argument is based on the assumption that forcing participants to use experimenterguided (random) retrieval "strategies," as is typically done in item-specific tests, disrupts participants' retrieval plans, regardless of whether part-list cues are provided. If true, then, in the 2-study-test and story conditions, the introduction of item-specific probes should not only eliminate the part-list cuing effect, but should also hamper performance in the no-part-list cuing condition. The results reveal such an effect. Both in the 2-study-test and story conditions, the presence of item-specific probes reduced recall performance in the no-part-list-cuing condition by about $25 \%$. By contrast, in the 1-study condition, in which strategies are supposed to play a minor role, the presence of itemspecific probes reduced recall nonsignificantly, by less than 5\% (see Figure 1). These results are consistent with the present view- that elaborated retrieval plans are not only disrupted when part-list cues are provided, but are already disrupted in the presence of item-specific probes.

In the item-specific probe conditions of the present experiment, only the noncues were tested in the part-list cuing condition, whereas noncues and cues were tested in the control condition, randomly intermixed. As a result, the noncues in the control condition may have suffered from output interference due to prior recall of some of the cue items (e.g., Smith, 1971), which may have reduced the part-list cuing effect. The nonexisting part-list cuing effect found in the 2-study-test and story conditions thus might have been caused by output interference. First, if output interference affected the results in the 2-study-test and story conditions, it should have affected the results in the 1-study condition as well. In the 1-study condition, however, significant part-list cuing arose. Second, output interference should also have affected the results when no item-specific probes were provided. In this case, however, reliable part-list cuing was observed in all three study conditions, indicating that it was not output interference that eliminated part-list cuing in some of the conditions of the present experiment.

We recently reported evidence that encoding influences part-list cuing. We showed that, dependent on encoding, part-list cuing can be transient or lasting (Bäuml \& Aslan, 2006). The present study supports this proposal by showing that, dependent on encoding, part-list cuing either disappears in the presence of item-specific probes or is maintained. Both lines of evidence are inconsistent with one-mechanism accounts of part-list cuing, like retrieval inhibition or strategy disruption, which predict that partlist cuing is transient (strategy disruption) or is lasting (retrieval inhibition), and that part-list cuing either occurs in the presence of item-specific probes (retrieval inhibition) or does not occur in their presence (strategy disruption). Both lines of evidence, however, are consistent with a twomechanism account, according to which retrieval inhibition and strategy disruption play in concert and operate in different encoding conditions.

\section{AUTHOR NOTE}

The research reported here was supported by a grant from the German Research Foundation (DFG) to K.-H.B. (FOR 448). We thank H. L. Roediger III, M. C. Anderson, and one anonymous referee for their comments on a previous version of the manuscript. Correspondence concerning this article should be addressed to K.-H. Bäuml, Department of Experimental Psychology, Regensburg University, 93040 Regensburg, Germany (e-mail: karl-heinz.baeuml@psychologie.uni-regensburg.de).

\section{REFERENCES}

Anderson, M. C. (2003). Rethinking interference theory: Executive control and the mechanisms of forgetting. Journal of Memory \& Language, 49, 415-445.

Anderson, M. C., BJork, R. A., \& Bjork, E. L. (1994). Remembering can cause forgetting: Retrieval dynamics in long-term memory. Journal of Experimental Psychology: Learning, Memory, \& Cognition, 20, 1063-1087.

Anderson, M. C., \& McCulloch, K. C. (1999). Integration as a general boundary condition on retrieval-induced forgetting. Journal of Experimental Psychology: Learning, Memory, \& Cognition, 25, 608-629.

Basden, B. H., Basden, D. R., \& Stephens, J. P. (2002). Part-set cuing of order information in recall tests. Journal of Memory \& Language, 47, 517-529.

Basden, D. R., \& Basden, B. H. (1995). Some tests of the strategy disruption interpretation of part-list cuing inhibition. Journal of Experimental Psychology: Learning, Memory, \& Cognition, 21, 1656-1669.

Basden D. R., Basden, B. H., \& Galloway, B. C. (1977). Inhibition with part-list cuing: Some tests of the item strength analysis. Journal of Experimental Psychology: Human Learning \& Memory, 3, 100-108.

Battig, W. F., \& Montague, W. E. (1969). Category norms for verbal items in 56 categories: A replication and extension of the Connecticut category norms. Journal of Experimental Psychology, 80, 1-46.

Bäuml, K.-H., \& Aslan, A. (2004). Part-list cuing as instructed retrieval inhibition. Memory \& Cognition, 32, 610-617.

Bäuml, K.-H., \& Aslan, A. (2006). Part-list cuing can be transient and lasting: The role of encoding. Journal of Experimental Psychology: Learning, Memory, \& Cognition, 32, 33-43.

B̈̈UmL, K.-H., Kissler, J., \& RAK, A. (2002). Part-list cuing in amnesic patients: Evidence for a retrieval deficit. Memory \& Cognition, 30, 862-870.

BÄUmL, K.-H., \& Kuhbandner, C. (2003). Retrieval-induced forgetting and part-list cuing in associatively structured lists. Memory \& Cognition, 31, 1188-1197.

Kimball, D. R., \& BJork R. A. (2002). Influences of intentional and unintentional forgetting on false memories. Journal of Experimental Psychology: General, 131, 116-130.

KISSLER, J., \& BÄUML, K.-H. (2005). Memory retrieval in schizophrenia: Evidence from part-list cuing. Journal of the International Neuropsychological Society, 11, 273-280.

Marsh, E. J., Dolan, P. O., Balota, D. A., \& Roediger, H. L., III (2004). Part-set cuing effects in younger and older adults. Psychology \& Aging, 19, 134-144. 
Neely, J. H., Schmidt, S. R., \& Roediger, H. L., III (1983). Inhibition from related primes in recognition memory. Journal of Experimental Psychology: Learning, Memory, \& Cognition, 9, 196-211.

Nickerson, R. S. (1984). Retrieval inhibition from part-set cuing: A persisting enigma in memory research. Memory \& Cognition, 12, 531-552.

Oswald, K. O., Serra, M., \& Krishna, A. (2006). Part-list cuing in speeded recognition and free recall. Memory \& Cognition, 34 518-526.

PeynircioĞLu, Z. F. (1989). Part-set cuing effect with word-fragment cuing: Evidence against the strategy disruption and increased-listlength explanations. Journal of Experimental Psychology: Learning, Memory, \& Cognition, 15, 147-152.

Reysen, M. B., \& NaIRne, J. S. (2002). Part-set cuing of false memories. Psychonomic Bulletin \& Review, 9, 389-393.

RoEDIGER, H. L., III (1973). Inhibition in recall from cueing with recall targets. Journal of Verbal Learning \& Verbal Behavior, 12, 644-657.

Roediger, H. L., III, \& NeELy, J. H. (1982). Retrieval blocks in episodic and semantic memory. Canadian Journal of Psychology, 36, 213-242.

Rundus, D. (1973). Negative effects of using list items as recall cues. Journal of Verbal Learning \& Verbal Behavior, 12, 43-50.

Sahakyan, L., \& Delaney, P. F. (2003). Can encoding differences explain the benefits of directed forgetting in the list method paradigm? Journal of Memory \& Language, 48, 195-206.

SCHEITHE, K., \& BÄUML, K.-H. (1995). Deutschsprachige Normen für Vertreter von 48 Kategorien. Sprache \& Kognition, 14, 39-43.

Serra, M., \& NAIRne, J. S. (2000). Part-set cuing of order information: Implications for associative theories of serial order memory. Memory \& Cognition, 28, 847-855.
SlameCKA, N. J. (1968). An examination of trace storage in free recall. Journal of Experimental Psychology, 76, 504-513.

Sмiтн, A. D. (1971). Output interference and organized recall from long-term memory. Journal of Verbal Learning \& Verbal Behavior, 10, 400-408.

Todres, A. K., \& Watkins, M. J. (1981). A part-set cuing effect in recognition memory. Journal of Experimental Psychology: Human Learning \& Memory, 7, 91-99.

Tulving, E. (1962). Subjective organization in free recall of "unrelated" words. Psychological Review, 69, 344-354.

WATKINS, M. J. (1975). Inhibition in recall with extralist “cues.” Journal of Verbal Learning \& Verbal Behavior, 14, 294-303.

ZELLner, M., \& BäUML, K.-H. (2005). Intact retrieval inhibition in children's episodic recall. Memory \& Cognition, 33, 396-404.

\section{NOTE}

1. In the present study, retrieval inhibition is assumed to affect the noncue items' representation itself, thus following the use of this term in the retrieval-induced forgetting literature (see Anderson, 2003, for a review). Retrieval inhibition thus differs from the retrieval competition account of Rundus (1973), which assumes that the strengthened cue items block access to the noncue items without affecting the noncues' representation itself.

(Manuscript received March 13, 2006; revision accepted for publication August 7, 2006.) 